\title{
International Financial Integration of the Indian Money Market
}

\author{
Steven Buigut (Corresponding Author) \\ Associate Professor of Economics, American University in Dubai. P.O Box 28282, Dubai, UAE
}

Tel: 971-4-318-3117Ｅ-mail: sbuigut@aud.edu

Vadhindran K. Rao

Associate Professor of Finance, Metropolitan State University, Minneapolis, USA

Tel: (612)-659-7291Ｅ-mail: Vadhindran.Rao@metrostate.edu

Received: September 11, 2010

Accepted: March 7, 2011

doi:10.5539/ijef.v3n4p170

\begin{abstract}
The study investigates whether the financial liberalization undertaken in India has resulted in integration of Indian markets with global markets. First, we investigate covered interest rate parity (CIP) between India and the US using 3 month interbank interest rates and 1 year swap rates. The results show little evidence of a long term equilibrium relationship between the domestic interest rate and the covered interest rate. The mostly negative results indicate the presence of a country risk premium and/or binding regulations on capital movements and/or binding restrictions on interbank borrowing and lending. Next, we use a Vector Error Correction Model (VECM) to study the dynamics between the Indian interest rate, the covered interest rate and the US interest rate. The results show some degree of cointegration among Indian and US interest rates, suggesting that linkages less direct than covered interest arbitrage may exist between US and Indian money markets.
\end{abstract}

Keywords: Financial integration, Covered interest parity, Swaps, India, VECM

\section{Introduction}

Indian financial markets have seen a lot of change since the nineties. Administered rates have been abolished, reserve requirements for banks have been decreased, foreign exchange regulations have been eased with the Rupee becoming fully convertible on the current account in the mid-1990s and moving towards fuller capital account convertibility. Also market-oriented reforms have been instituted including measures to protect investors. The Reserve Bank of India (RBI) Reports on Currency and Finance (RBI,2005-06; 2006-08) contain details regarding such liberalization. Thus, it is generally acknowledged that Indian financial markets have been opened up to a significant extent (see Patnaik and Vasudevan, 1999; Jain and Bhanumurthy, 2005 and Patnaik and Shah, 2010).

The question of interest is whether the financial liberalization undertaken thus far has resulted in financial integration of Indian markets with global markets. The answer to this question has important policy implications. As is well known from the theory of the impossible trinity, the more integrated markets are, the less the country can simultaneously control both interest rates and exchange rates. Shah and Patnaik (2005) and Prasad (2009) provide discussions of policy challenges in managing financial integration in the Indian context.

There are several approaches to investigating global financial integration (Obstfeld and Taylor, 2004 provides a good review). One such approach is based on Covered Interest Parity (CIP):

$$
\left(1+i_{d}\right)=(1 / S)\left(1+i_{f}\right) F
$$

Above, $i_{d}$ is the risk-free domestic rate of return for a given time horizon, $i_{f}$ is the corresponding foreign rate of return, $S$ is the direct spot exchange rate (units of domestic currency per unit of foreign currency) and $F$ is the forward exchange rate for the given time horizon. According to CIP, under ideal conditions (such as financial integration and absence of market frictions), the risk-free return from investing a unit of the domestic currency will equal the risk-free return from converting a unit of the domestic currency into foreign currency at the spot exchange rate, investing the proceeds in the money market of the foreign currency, and covering the foreign exchange risk with an appropriate forward contract. The CIP condition relies on arbitrage activity to make it work. Therefore, an important prerequisite for CIP to hold is that there should be minimal impediments to capital flows across borders. In practice, even if financial markets are open, the presence of market frictions such as taxes, transactions costs and differences in default risk would cause some deviations from parity. Subject to this caveat, a violation of CIP reflects barriers to capital mobility and therefore lack of financial integration between the countries concerned. 


\section{Literature Survey}

There is an extensive literature on using CIP to test for financial integration (see Sarno and Taylor, 2002 for a good survey). A classic study by Frenkel and Levich (1975) is based on Euro-deposit rates from the 1960's on the US dollar, the Canadian dollar and the British pound. The study argues that almost all of the apparent deviations from CIP could be attributed to transactions costs. Other notable studies based on developed markets include Frenkel and Levich (1981), Clinton (1988), Popper (1993) and Takezawa (1995). For the most part, these studies concluded that CIP deviations were not economically significant. More recently, Obstfeld and Taylor (2004) use monthly data of the US dollar and German mark against the British pound, from 1921 through 2003, and report that deviations have virtually disappeared since 1980. Batten and Szilagyi (2006) use daily time series data for the USD/JPY forward market and find that CIP deviations have been largely eliminated by 2000. Thus, many of the studies set in advanced economies have found support for the CIP.

A few studies have also been carried out in the Indian context. Using the Corporate Deposit (CD) rate as the domestic borrowing rate and USD Libor as the foreign interest rate, Varma (1997) found CIP deviations to be several times larger than the numbers reported for OECD markets, and attributed this to market frictions. This result was supported by Bhoi and Dhall (1998), who conclude that Indian financial markets were far from being integrated with global markets, although the various domestic markets (namely, the money market, the government bond market and the corporate bond market) appeared to be integrated amongst themselves. Mishra et al (2001) provide further confirmation of CIP failure. However, Jain and Bhanumurthy (2005) found evidence of cointegration between the Indian call money rate, US Dollar Libor and the Dollar-Rupee exchange rate. They conclude that "the degree of integration seems to be growing," though the integration process is far from complete. Sharma and Mitra (2006) analyzed the factors driving the forward premium of the dollar against the rupee and found that the key driver is the interest rate differential, which is supportive of CIP. However, they found that other variables they used in the analysis such as net portfolio flows, the current account balance and exchange rate movements also showed some explanatory power. Further, when they ran separate regressions for an earlier and later period, they found a diminished role for the interest rate differential in the later period and concluded that forward premia are increasingly being influenced by demand and supply.

In a more recent study, George and Mallik (2009a) conclude that central bank actions to smooth interest rates and prices drive a wedge between the forward premium and the interest rate differential. In a related study, George and Mallik (2009b) find that apart from the interest rate differential, the forward premium is also influenced by international oil prices, the real effective exchange rate (REER) of the rupee and current account openness. They note that the forward premia appear to be more strongly influenced by current account transactions than by capital flows. Hutchison et al (2009) uses the Self Exciting Thresold Autoregression (SETAR) methodology to estimate a band around the CIP mark with the following properties: deviations within the band follow a random process, while deviations outside the band set in motion an autoregressive adjustment process towards the boundaries. They interpret the band as follows. For CIP deviations within the band, arbitrage attempts are unprofitable owing to market frictions. Period by period movements within the band are accordingly random. Outside the band, the deviations are large enough to render arbitrage profitable, and activity by arbitrageurs therefore pushes rates to adjust such that deviations revert towards the closer boundary. They allow for structural breaks and estimate separate bands for various subperiods, namely, January 1999 to January 2003, Janaury 2003 to April 2005 and April 2005 to January 2008. They find that the bandwidth is narrower in the second and third subperiods as compared to the first. Further, they find that reversion to the boundaries is relatively rapid if the deviation moves outside the band. Overall, they conclude that barriers to arbitrage are lower post-2003.

The results from the SETAR methodology are highly interesting, but also raise some questions. Firstly, while the mean deviation is lower in the third subperiod than in either of the earlier subperiods, the bandwidth estimated for the third subperiod is wider than that estimated for the second. Therefore, barriers to arbitrage are not decreasing in a monotonic manner. Secondly, even in the last subperiod, the estimated bandwidth is as large as $1.27 \%$. As discussed in more detail later, this is much larger than is typically estimated for advanced economies, and it therefore seems unlikely that transaction costs can account for CIP failure. A possible reason for such wide deviations from CIP is capital controls. Indeed, as noted by Hutchison et al (2009), in the pre-2003 period, the bandwidth was skewed towards the lower threshold reflecting the fact that the covered interest rate was higher than the domestic interest rate, thereby suggesting that capital controls were binding on outflows. Since then, the bandwidth has been skewed towards the upper threshold (as the domestic interest rate has been higher than the covered interest rate for the most part) suggesting that controls have been binding on inflows. To sum up, most of the studies set in the Indian context have found mixed results. The more recent studies seem to indicate some degree of financial integration, but also suggest that integration is far from complete. 
In this study, we take a fresh look at this question using a different approach. First, most prior Indian studies have been based either on the Indian Corporate Deposit rate or the T-bill rate. How well these rates reflect actual market opportunities for financial institutions in India is debatable. For example, an Indian bank cannot obviously raise funds at the T-bill rate. However, researchers have made use of proxies such as these mainly because of the lack of a well-developed term interbank market in India. In this study, we look at both short term ( 3 month) rates and a relatively longer term 1 year rate. For the 3 month period, we use the 3 month Mibor (interbank rate) as the domestic interest rate and the 3 month Libor as the foreign interest rate. A shortcoming of using the 3 month Mibor is that the term interbank money market in India is under-developed and illiquid. We therefore supplement these results by carrying out tests on 1 year rates relating to the Indian interest rate swap market. To our knowledge, this is the first study in the Indian context to investigate CIP and financial integration based on Indian interest rate swaps. Another noteworthy feature of the study is that the relationships tested are derived from arbitrage considerations. As elaborated upon later, it is possible for banks in India to carry out transactions which can, in effect, enable them to obtain term funding and make term investments at interest rates approximately equal to Overnight Indexed Swap (OIS) rates. We therefore propose that the Indian OIS curve is the best (though imperfect) measure of money market rates faced by an Indian bank. Further, using swap rates also allows us to conduct relatively longer horizon tests.

To sum up, our first approach to studying financial integration is based on CIP and the question is whether a stable long term relationship exists between the domestic interest rate and the covered interest rate, and whether the spread has decreased over time. Our second approach is to widen the focus from arbitrage considerations to other kinds of linkages between domestic and foreign rates. Apart from arbitrage, domestic and foreign interest rates may be linked due to trade-related reasons and adjustments undertaken by portfolio investors. We therefore use a Vector Error Correction Model (VECM) to analyze the dynamics of and investigate possible cointegration between US and Indian rates.

\section{Indian swaps}

An important part of this study is based on interest rate swaps. Thus we start with a brief introduction to the Indian swap market. A swap is a contract between two parties to exchange cash flows based on a formula. A plain vanilla interest rate swap (IRS) involves one party receiving a series of fixed cash flows and paying variable cash flows based on a floating interest rate applied to a notional amount. Interest rate swaps were first introduced in India in 1999, and are largely based on one of two benchmarks - overnight Mibor (Mumbai Interbank Offer Rate published by the National Stock Exchange or NSE), and the six-month Mifor (Mumbai Interbank Forward Offer Rate), which is a rate implied from the dollar-rupee foreign exchange (FX) market. Swaps based on the overnight Mibor are referred to as Mibor swaps, or alternatively as Overnight Indexed Swaps (OIS), and those based on the six-month Mifor are referred to as Mifor swaps. It is worth noting in this connection that the reason why the swap market is mostly based on one or the other of these two particular benchmark rates is primarily due to the lack of a well-developed term interbank market. In contrast, the overnight call market is active and liquid and provides a credible benchmark, namely overnight Mibor. As for Mifor, this is an innovation that is perhaps unique to the Indian market. It is not directly a market-determined interbank term rate. For maturities up to a year, it is defined and calculated (roughly) as the sum of the corresponding US Dollar Libor (London Interbank Offer Rate) and the forward premium on the US Dollar against the Indian Rupee (INR). For example, the 6 month Mifor (on which Mifor swaps are typically based) is calculated (approximately) as the sum of US Dollar Libor and the 6 month Dollar-Rupee forward premium. Therefore, the 6 month Mifor is essentially a covered interest rate. The concept of Mifor rates overcomes the limitation of the lack of a developed term interbank market by exploiting the availability of currency forward premia from a highly active domestic foreign exchange market.

The objective of this study is to determine integration, or the lack of it, of the rupee money market with that of the US dollar. We approach this question by investigating the relationship between the two Indian swap curves, namely the Mibor swap curve (OIS curve) and the Mifor swap curve. Under ideal conditions, we would expect almost complete convergence between the two swap curves. More realistically, after taking into account market frictions, testing for stationarity/convergence of the spread between Mibor and Mifor rates of corresponding maturities is effectively a test of covered interest rate parity and financial integration. Consider for example the 1 year Mibor swap (OIS) rate. It is a market-determined rate that contains the market's expectations regarding the average overnight call money rate over the next one year. As shown below, there is a good argument to treat OIS rates as the best available proxies for term money market rates. The 1 year Mifor swap rate on the other hand will reflect market expectations about future US Dollar Libor rates and the forward premia on the US Dollar in the foreign exchange market. Despite the fact that the two swap rates appear to be based on very different economic variables, there is an arbitrage relationship between them. If the 1 year Mifor swap rate is lower than the 1 year Mibor swap (OIS) rate, then a bank with access to both domestic and international money markets can:

(i) raise term rupee funds at a covered interest rate equal to the 1 year Mifor swap rate by 
a) Borrowing dollars at 6 month Libor and entering into a 6 month sell/buy dollar swap (with the interest payment in dollars due 6 months later covered with a forward contract)

b) Repeating this transaction after six months, and

c) Entering into a 1 year pay fixed, receive floating Mifor swap.

Note that payments received every six months on the floating leg of the Mifor swap will exactly offset the dollar payments to be paid every six months (the forward premium on the FX swap and interest payment on the foreign borrowing).

(ii) invest the rupee funds at the 1 year Mibor swap (OIS) rate by

a) Investing the funds in the Indian overnight money market

b) Rolling the funds over on a daily basis, and

c) Entering into a 1 year receive fixed, pay floating Mibor swap (OIS) rate

Note that the interest received from the rolled-over overnight investments will (more or less) offset the payment required to be made on the floating leg of the Mibor swap (OIS). Of course, the offset may not be exact as it may not be possible to invest each day in the overnight market at exactly the same rate as the Mibor fixing for the day. This point is discussed briefly later.

The transactions to be undertaken in the case where the 1 year Mifor swap rate is higher than the 1 year Mibor swap (OIS) rate are the opposite of the above. In such a case, a bank with access to both domestic and international money markets can:

(i) raise term rupee funds at an interest rate equal to the 1 year Mibor swap (OIS) rate by

a) Borrowing rupees in the overnight money market

b) Rolling over the borrowing on a daily basis, and

b) Entering into a 1 year pay fixed, receive floating Mibor swap (OIS).

(ii) invest the rupee funds so as to earn the 1 year Mifor rate by

a) Entering into a series of buy/sell dollar swaps every 6 months

b) Investing the dollar proceeds for 6 months at a time to earn 6 month Libor, and

c) Entering into a 1 year receive fixed, pay floating Mifor swap.

Thus, arbitrage considerations require equality between the Mibor (OIS) and the Mifor swap curves in equilibrium. It must be recognized that such arbitrage is not strictly riskless, primarily because there will be in practice some difference between the actual overnight rate at which the arbitrageur borrows or lends each day and the daily overnight Mibor fixing on which the OIS cash flows are calculated. There is a similar problem with respect to Libor borrowing and lending as well. But the risk (we propose) may be ignored to a first approximation. The uncertainty regarding cash flows as a result of this practical problem should be small, given the averaging effects on the deviations over the entire life of the swap. The above example is based on a 1 year term. Of course, the same sort of transactions can also be carried out using swaps of longer maturity.

\section{Data and methodology}

The data consist of the following monthly time series: rupee 3 month Mibor (an interbank rate), the 1 year Mibor swap (OIS) rate, the 3 month Mifor rate, the 1 year Mifor swap rate, the 3 month Libor, and the 1 year dollar swap rate. The raw data were sourced from Reuters, and converted into continuously compounded rates. The data cover the period from October 2002 through September 2009. Summary statistics for the domestic interest rate (hereafter referred to as Mibor), the covered interest rate (Mifor) and the US interest rate (Libor) are provided. The first set of variables consists of the 3-month Mibor, the 3-month Mifor and the 3-month dollar Libor (Table 1a). The second set of variables includes the one-year Mibor swap (OIS) rate, the one-year Mifor swap rate and the one-year US Swap rate (Table 1b). Further, the tables also contain summary statistics for the spread between the domestic and covered interest rates, which is also referred to as the Covered Interest Differential (CID).

Comparing the Indian 3 month rates (Mibor and Mifor) with the 3 month dollar Libor, we see that the standard deviations of the Indian interest rates are comparable to that of 3 month Libor. Similarly, the standard deviations of the Indian swap rates are comparable to that of the US swap rate. It is interesting to observe that 3 month Libor and the 1 year US swap rate show similar levels of negative kurtosis. Regarding the Indian rates, 3 month Mibor and 1 year Mifor show negative kurtosis, while 1 year Mibor (OIS rate) and 3 month Mifor show positive kurtosis. The 
reason for this is not readily apparent. Also, both 3 month and 1 year Indian rates show more skewness than the corresponding dollar interest rate.

A necessary condition for two variables to be (uniquely) cointegrated is that each should be integrated of order 1, i.e. I(1). Table 2 provides the results of unit root tests carried out using the Dickey-Fuller approach. From Table 2, the results indicate that the test statistic cannot reject the null of I(1) in levels but rejects the null that the first difference is I(1) at 1\% significance. Hence we conclude that Mibor, Mifor and Libor are each I(1) both for the 3 month and 1 year terms.

\subsection{Tests of cointegration/convergence between Mifor and Mibor}

We next focus on testing CIP. Our first approach is to run stationarity and regression-based tests on the spread between the Mibor and Mifor rates. Under ideal conditions, the spread would be zero. In the presence of market frictions, we would expect the spread to be contained within a band provided markets are integrated to a reasonable extent. The points of interests are (a) the width of this band (or the mean and standard deviation of the spread) and (b) whether the spread is either stationary or getting smaller over time. Accordingly, for the 1-year data set we carry out a set of tests (a similar set of tests are carried out for the 3 month data set):

a) Whether the 1 year OIS rate and the 1 year Mifor rates are cointegrated

b) Whether the spread is stationary

c) Whether the spread is getting smaller.

We first use the Engle-Granger two-step procedure to test for cointegration, which consists of regressing one variable on the other and testing the residuals for cointegration. However, it is well known that a univariate cointegration testing methodology, such as the Engle-Granger procedure mentioned above may be inefficient if the variables are jointly endogenous. We therefore use the tests developed in Johansen (1988), Johansen (1994) and Johansen and Juselius (1990) to further investigate possible cointegration between the Mifor and Mibor rates. A brief summary of the Johansen testing methodology follows below.

If $\mathrm{X}$ is an $n$ dimensional column vector of $\mathrm{I}(1)$ variables, a VAR(p) model can be reformulated into vector error correction model (VECM) of the form;

$$
\Delta X_{t}=\pi X_{t-1}+\sum_{i=1}^{p-1} \pi_{i} \Delta X_{t-p}+\mu_{0}+\mu_{1} t+\varepsilon_{t}
$$

$\pi=\alpha \beta^{\prime}$, where $\alpha$ represents the speed of adjustment to disequilibrium and $\beta$ is a matrix of long-run coefficients, both full rank $n \times r$ matrices. The $\mu_{0}$ and $\mu_{1}$ are $n \times 1$ vectors of constant and trend coefficients, $\varepsilon_{t}$ is a $n \times 1$ error vector assumed multivariate normal, mean zero and variance $\Omega$ that is independent across time periods. If the rank is zero $(r=0)$ then $\pi=0$, which means there is no linear combination of $X_{t}$ that is stationary. If the rank of $\pi$ matrix is equal to $n$ then $X_{t}$ is a stationary process. In the intermediate case, $0<r<n$, there are $r$ stationary linear combinations of the elements of $X_{t}$ and $n-r$ stochastic trends (Haug, et al. 2000). Given $\pi=\alpha \beta^{\prime}$, the relation between $\alpha$ and the deterministic term, $\mu_{t}=\mu_{0}+\mu_{1} t$, is crucial for the properties of $X_{t}$ process. Five submodels are commonly derived from these interactions. These submodels are derived in detail in Johansen (1994), Haug et al. (2000) and Koukouritakis and Michelis (2008). We give the results from these five submodels following the ordering in Haug et al. (2000) and Koukouritakis and Michelis (2008) from the most to least restrictive. A summary of these submodels are as follows:

Model 0: $\mu_{t}=0, X_{t}$ has no deterministic terms and all stationary components have zero mean. This is termed trend (none) in Stata10 program. The other submodels that follow are termed restricted constant, unrestricted constant, restricted trend, and unrestricted trend for models $1^{*}, 1,2^{*}$, and 2 respectively in stata.

Model $1^{*}: \mu_{t}=\alpha \beta_{0}, X_{t}$ has neither a quadratic trend nor a linear trend. But both $X_{t}$ and the cointegrating relation $\beta^{\prime} X_{t}$ are allowed a constant term.

Model 1: $\mu_{t}=\mu_{0}, X_{t}$ has a linear trend, but $\beta^{\prime} X_{t}$ does not.

Model $2^{*}: \mu_{t}=\mu_{0}+\alpha \beta_{1} t, X_{t}$ has no quadratic trend but has linear trend that is present in the cointegrating relations.

Model 2: $\mu_{t}=\mu_{0}+\mu_{1} t$, allows for quadratic trend in $X_{t}$ but $\beta^{\prime} X_{t}$ has only a linear trend. 
Testing for cointegration amounts to finding the number of $r \leq(n-1)$ linearly independent columns in $\pi$ (i.e. the rank of $\pi$ ). The trace statistic $\left(\lambda_{\text {trace }}\right.$ ) (Johansen and Juselius, 1990) tests the null hypothesis that the number of distinct cointegrating vectors is less than or equal to $r$ against a general alternative that rank $(\pi)=n$. This value is equal to zero when all the eigenvalues, $\lambda_{i}$, are zero. The further away the estimated roots (eigenvalues) are from zero the more negative is $\ln \left(1-\hat{\lambda}_{i}\right)$ and the larger the trace statistic.

$$
\lambda_{\text {trace }}(r)=-T \sum_{i=r+1}^{n} \ln \left(1-\hat{\lambda}_{i}\right)
$$

An alternative test, the maximum eigenvalue statistic $\left(\lambda_{\max }\right)$, tests the null that the number of cointegrating vectors is $r$ against the alternative of $r+1$ cointegrating vectors.

$$
\lambda_{\max }(r, r+1)=-T \ln \left(1-\hat{\lambda}_{r+1}\right)
$$

where $\hat{\lambda}_{i}$ are the estimated values of the eigenvalues (characteristic roots) obtained from the $\pi$ matrix, and $\mathrm{T}$ is the number of usable observations. Besides testing for cointegration between the domestic and covered interest rates, we also directly test for stationarity of and a possible trend in the spread between these rates (or the CID) as well as for stationarity of and trend in the absolute value of the spread.

\subsection{Further cointegration tests between Indian and US swaps}

The second approach is to use a VECM to investigate the dynamics of Indian and US interest rates. The main point of interest is the extent, if any, to which Indian and US interest rates are cointegrated. A VECM approach is used to test for cointegration among the 3 month ( 1 year) Indian rate, 3 month (1 year) covered rate and the corresponding US rate. Regardless of whether or not CIP holds, US and Indian interest rates may still share a common stochastic trend. The objective of the VECM approach is to test for the existence of such a trend.

\section{Results}

\subsection{Cointegration and convergence test results.}

We look first at the results for the cointegration test, mentioned in section 3.1, investigating the relationship between the domestic interest rate (Mibor) and the covered interest rate (Mibor). Table 3a contains the results of the two-step Engle-Granger test for cointegration. This two-step procedure consists of regressing one rate on another and testing the residuals for stationarity. Testing for stationarity is carried out using the Augmented Dickey-Fuller (ADF) methodology, which is similar to the Dickey-Fuller test except that the Dickey-Fuller regression is expanded to include as many lags as are required to remove autocorrelation in the residuals. The test statistics for both 3 month rates and 1 year rates are each greater than their respective critical values. Therefore the null hypothesis of lack of cointegration cannot be rejected at the $5 \%$ level of significance. Results from the Johansen tests are presented in Table $3 \mathrm{~b}$. For 1 year rates, the lag order selection criteria, namely the Akaike information criterion (AIC) and the log likelihood ratio (LR), indicate an optimal lag length of four. So we use four lags in the test for cointegration for the 1 year data. For the 3 month data, the AIC indicates an optimal lag length of three while the LR indicates two. To be conservative we use three lags in the test for cointegration for the 3 month data. For brevity only the rank $(r)$ suggested by the trace and maximum eigenvalue tests are given in Table $3 b$. For both the 3-month and 1-year data sets, the results for all the five sub models obtained (Table $3 b$ ) from both the maximum eigenvalue and trace tests suggest that the rank is zero at the $1 \%$ and $5 \%$ levels. Clearly, the indication here is that the two variables are not cointegrated. Thus, domestic and covered interest rates do not appear to share a stable, long term, linear relationship.

We next provide results of the test on the stationarity (Table 4) of the spread (the difference) between Mibor and Mifor. Let Spread = Mibor - Mifor. An Augmented Dickey Fuller (ADF) test is used to test for stationarity of Spread. We also test the stationarity of the absolute spread. In both cases a trend variable is included. For both the 1-year and 3-month periods, the null hypothesis of unit root for the spread cannot be rejected, but is rejected for the first difference of the spread (last two columns of Table 4). Hence the spread is not stationary but I(1). Given the lack of cointegration between the domestic and covered interest rates found earlier, this is expected. Figure 1 shows the behavior of the spread over time. We also use ADF to test stationarity of the absolute value of spread (abspread). The results are shown in the third row of Table 4. Like the spread, the absolute spread is not stationary but I(1). The coefficient on the trend variable in the ADF test in all cases is highly insignificant.

To test if the lack of cointegration between the two variables may be due to the recent financial crisis, we re-estimate the results shown in this section using a subsample spanning the period October 2002 through June 2007. The results obtained for cointegration are basically similar to those of the full sample presented in Table $3 \mathrm{~b}$. 
Specifically, the results show no indication of cointegration between the two variables, and neither the spread nor the absolute spread is stationary. Both were found to be I(1). We therefore find little evidence in support of the hypothesis that the lack of a long term relationship is a result of the recent crisis. The trend evidence however suggests that the spread (and absolute spread) was declining prior to the crisis. The coefficient on the trend variable in the ADF is significant for both ( $\mathrm{p}$ values of 0.018 and 0.066 respectively).

\subsection{Further cointegration test results}

The results for the cointegration test mentioned in section 3.2 are discussed in this subsection. In this approach, the dynamics of the set of three variables: the domestic interest rate (Mibor), the covered interest rate (Mifor), and the US interest rate (Libor) is analyzed using both 3 month and 1 year rates. We use a three variable VECM as in equation (2) in section 3.1, where $\mathrm{X}$ is a column vector consisting of the three I(1) variables: Mibor, Mifor, and Libor. The LR and AIC test indicate an optimal lag length of four for the 1 year data set and two for the 3 month data set respectively. For brevity only the rank $(r)$ suggested by the trace and maximum eigenvalue tests are given in Table 5. Take the one- year period data first. The result obtained from the max test statistics, for all sub models, is that the rank is zero at the $1 \%$ and $5 \%$ levels. However the trace statistic indicates a rank of one for some of the submodels at the $5 \%$ level. Thus, the results of the trace test conflict with those of the other. For the three-month data, the results in favor of cointegration are even weaker. Thus overall, the three variables seem to be weakly, if at all, cointegrated.

\section{Discussion}

We have investigated the relationship between the 3 month ( 1 year) domestic interest rate and the 3 month ( 1 year) covered interest rate. Testing for cointegration/convergence between the domestic and covered interest rates is a test of covered interest rate parity and thus of financial integration of the Indian rupee money market with the US dollar money market. Of course, given the fact of restrictions on convertibility of the rupee, we do not expect perfect integration. However, restrictions on capital movements have been considerably eased over the last decade and the question is rather whether this liberalization has resulted in any appreciable degree of integration. Further, prior research suggests that Indian markets may show a greater degree of de facto integration with global markets despite a lack of de jure openness (Patnaik and Shah, 2010). A related question is whether the degree of integration has been increasing over time.

The results of the current study are not highly supportive of covered interest rate parity. There is a substantial spread between domestic interest rates and corresponding covered interest rates. For example, the average spread between the 1 year Mibor swap (OIS) rate and the 1 year Mifor swap rate is around 85 basis points. Further, this is a long-lasting phenomenon, not something that exists only for short periods of time before getting arbitraged away. Nor is there any evidence that the spread is getting smaller with time. Such a long-lived, wide spread reflects impediments to arbitrage rather than temporary market inefficiency. Theoretically, the possible impediments are taxes, transactions costs, capital market regulations, credit (counterparty) risk and country risk. Let us consider each of these. Withholding taxes are low in both the US and India, and the two countries have a tax treaty that protects investors against double taxation (see the Tax Convention with the Republic of India available at: http://www.unclefed.com/ForTaxProfs/Treaties/inditech.pdf for information relating to the US India tax treaty effective from January 1991). Therefore, CIP failure cannot be attributed to taxes. Transactions costs are unlikely to account for much more than 10 basis points given that studies carried out on pairs of advanced economies reveal CIP deviations of only such a magnitude. For example, Frenkel and Levich (1981) estimate transactions costs using bid-ask spreads for the US dollar-Canadian dollar pair to be $0.125 \%$ per annum. Estimates by Clinton (1988) for a group of five Euro-currencies against the US dollar are even smaller at $0.06 \%$, and the estimate by Balke and Wohar (1997) for the US-UK currency pair is only marginally higher at $0.08 \%$.

Capital Market controls and risk considerations (counterparty and country risk) remain possibilities. Consider the current situation in which the Mifor swap rate is lower than the OIS rate. Arbitraging this discrepancy requires borrowing dollars at (close to) Libor, investing the borrowed funds in the Indian money market, and covering the foreign exchange risk by purchasing dollars forward. Indian banks cannot exploit this opportunity, as they are not likely to be able to raise dollar funding in the Eurodollar interbank market at anything close to Libor. However, there are many foreign banks that operate in India, and at least some of these banks should be able to obtain overseas dollar funding at Libor. Anecdotal evidence indicates that some foreign banks are indeed exploiting this opportunity, but the scale of this activity is clearly not large enough to eliminate the spread. There are reasons why foreign banks are not likely to be able to undertake this arbitrage to the fullest extent. Firstly, there are limits imposed by the central bank (Reserve Bank of India) on both the amount of overseas borrowing as well as on the amount of domestic overnight lending (refer to Mohan, 2007 and Thorat, 2010 for a summary of main regulations in this 
regard). The Master Circulars issued by Reserve Bank of India on (i) Call/Notice Money Market Operations in 2009 (Reserve Bank of India, 2009) and (ii) Risk Management and Interbank Dealings in 2006 (Reserve Bank of India, 2006) contain the original directives issued by the Central Bank. The Reserve Bank of India (2008-2009) annual report provides updated regulatory measures relating to money and foreign exchange markets. Further, beyond a certain point, foreign banks will need substantially higher returns from local lending in Indian money markets funded by overseas borrowing. To put it differently, foreign banks would run up against internal risk limits, such as counterparty (credit) risk limits with respect to lending in Indian money markets and cross-currency funding limits with respect to funding positions in one currency by borrowing in another. Lastly, it is also possible that foreign banks are curbing such arbitrage transactions to avoid incurring the displeasure of Indian monetary authorities.

Determining which of the constraints is/are binding is left for future research. One argument why counterparty risk is unlikely to be an important is that arbitrageurs can always lend in the Indian money market on a collateralized basis, for example, using "Collateralized Borrowing and Lending Obligations", a money market instrument introduced by the Reserve Bank of India in the fiscal year 2002-03 (refer to the Reserve Bank of India, 2005-2006 Report on Currency and Finance). That leaves controls on overseas borrowing, overnight lending restrictions and country risk. If foreign banks are using external borrowing to the limit, then the reason for CIP violation is probably capital controls on such borrowing. If that is not the case, but foreign banks are using overnight lending limits to the fullest extent, then the reason could be overnight lending restriction. If neither of the above is true, then it must be country risk.

The second set of tests was on the relationship between US and Indian interest rates. VECM results indicate some degree of three-way cointegration between the domestic, covered and dollar (foreign) interest rate. This is especially interesting given lack of cointegration between the domestic interest rate and the covered interest rate. Taken in conjunction, these results indicate that the dollar-rupee forward premium is at least partly driven by factors other than the interest rate differential. This is consistent with previous studies such as Sharma and Mitra (2006) who conclude that the forward premia on the dollar against the rupee, in addition to being influenced by the interest rate differential, are also affected by hedging demand and supply conditions, and George and Mallik (2009b) who find that current account-related factors have an important influence on forward premia.

Lastly, the existence of cointegration (however weak) between Indian and US interest rates suggests that there may be channels other than arbitrage that link Indian and global markets. Despite not being cointegrated with each other, it is possible that domestic and covered interest rates may share a common stochastic trend with US rates. The link could be trade-related. Alternatively, changes in US rates may lead to adjustments by multinational firms and portfolio investors. Investigating the nature of these possible linkages is left for future research.

\section{References}

Batten, J. A., \& Szilagyi, P. G. (2006). Arbitrage, covered interest parity and long-term dependence between the US Dollar and the Yen. The Institute for International Integration Studies Discussion Paper Series, IIIS Discussion Paper No. 128.

Bhoi, B. K., \& Dhall, S. C. (1998). Integration of financial markets in India: An empirical evaluation. RBI Occasional Papers, 19(4), 345-380.

Clinton, K. (1988). Transactions costs and covered interest arbitrage: Theory and evidence. Journal of Political Economy, 96(2), 358-370. http://dx.doi.org/10.1086/261540

Frenkel, J. A., \& Levich, R. M. (1975). Covered interest arbitrage: Unexploited profits? Journal of Political Economy, 83(2), 325-338. http://dx.doi.org/10.1086/260325

Frenkel, J. A., \& Levich, R. M. (1981). Covered interest arbitrage in the 1970's. Economics Letters, 8(3), 267-274. http://dx.doi.org/10.1016/0165-1765\%2881\%2990077-X

George, P., \& Mallik, D. (2009a). Monetary policy and international financial integration - The case of India. The Curie Journal, Vol 2 (III), BITS, Pilani.

George, P., \& Mallik, D. (2009b). Covered interest parity and international financial integration: The case of India. The ICFAI Journal of Applied Finance, 15(2), 58-74.

Haug, A. A., MacKinnon, J. G., \& Michelis, L. (2000). European monetary union: A cointegration analysis. Journal of International Money and Finance, 19(3), 419-432. http://dx.doi.org/10.1016/S0261-5606\%2800\%2900013-9

Hutchison, M., Kendall. J., Pasricha, G., \& Singh, N. (2009). Indian capital control liberalization: Evidence from the NDF markets. National Institute of Public Finance and Policy Working Paper No. 2009-60, New Delhi. 
Jain, S., \& Bhanumurthy, N. R. (2005). Financial markets integration in India. Asia-Pacific Development Journal, $12(2), 15-32$

Johansen, S. (1988). Statistical analysis of cointegration vectors. Journal of Economic Dynamics and Control, 12(2-3), 231-254. http://dx.doi.org/10.1016/0165-1889\%2888\%2990041-3

Johansen, S. (1994). The role of the constant and linear terms in cointegration analysis of nonstationary variables. Econometric Reviews, 13(2), 205-229. http://dx.doi.org/10.1080/07474939408800284

Johansen, S., \& Juselius, K. (1990). Maximum likelihood estimation and inference on cointegration with applications to the demand for money. Oxford Bulletin of Economics and Statistics, 52(2), 169-210. http://dx.doi.org/10.1111/j.1468-0084.1990.mp52002003.x

Koukouritakis, M., \& Michelis, L. (2008). The term structure of interest rates in the 12 newest EU countries. Applied Economics, 40(4), 479-490. http://dx.doi.org/10.1080/00036840600690249

Mishra, A. K., Sebastian, V. J., \& Ramanathan, A. (2001). Test of covered interest parity between U.S. Dollar and Indian Rupee. The Indian Journal of Economics, Vol LXXXII, No. 324.

Mohan, R. (2007). Development of financial markets in India. Address by Deputy Governor, Reserve Bank of India at the First Indian-French Financial Forum, Mumbai, May 16, 2007, Reserve Bank of India Bulletin.

Obstfeld, M., \& Taylor, A. M. (2004). Global capital markets: Integration, crises and growth. Cambridge: Cambridge University Press, UK. http://dx.doi.org/10.1017/CBO9780511616525

Patnaik, I., \& Shah, A. (2010). Why India choked when Lehman broke. NIPFP-DEA Research Program on Capital Flows and their Consequences, National Institute of Public Finance and Policy, Working Paper 2010-63.

Patnaik, I., \& Vasudevan, D. (1999). Interest rate determination: An error correction model. National Council of Applied Economic Research, Discussion Paper DP 020005.

Popper, H. (1993). Long-term covered interest parity - Evidence from currency swaps. Journal of International Money and Finance, 12(4), 439-448. http://dx.doi.org/10.1016/0261-5606\%2893\%2990005-V

Prasad, E. S. (2009). India's approach to capital account liberalization. The Institute for the Study of Labor (IZA), Discussion Paper No. 3927, Bonn.

Reserve Bank of India. (2005-2006; 2006-2008). Report on Currency and Finance.

Reserve Bank of India. (2006). Master circular on risk management and inter-bank dealings RBI/2006-07/24, Master Circular No. /06/2006-07 July 1, 2006.

Reserve Bank of India. (2008-2009). Annual report.

Reserve Bank of India. (2009). Master circular on call/notice money market operations, RBI/2009-10/46 FMD; MSRG. No. 36/02.08.003/2009-10 July 1, 2009.

Sarno, L., \& Taylor, M. P. (2002). The Economics of Exchange Rates. Cambridge: Cambridge University Press.

Shah, A., \& Patnaik, I. (2005). India's experience with capital flows: The elusive quest for a sustainable current account deficit. NBER Working Paper No. 11387.

Sharma, A. K., \& Mitra, A. (2006). What drives forward premia in Indian forex market? Reserve Bank of India Occasional Papers, Vol. 27, No. 1 and 2.

Takezawa, N. (1995). Currency swaps and long-term covered interest parity. Economics Letters, 49(2), 181-185. http://dx.doi.org/10.1016/0165-1765\%2895\%2900664-2

Thorat, U. (2010). Indian perspective on banking regulation. Address by deputy governor, Reserve Bank of India, Conference on 'Financial Sector Regulation and Reforms in Asian Emerging Markets,' February 8, 2010, Mumbai. http://www.rbi.org.in/scripts/BS_SpeechesView.aspx?id=482

Varma, J. R. (1997). Indian money market: Market structure, covered parity and term structure. The ICFAI Journal of Applied Finance, 3(2), 1-10. 
Table 1a. Summary Statistics of 3 Month Rates (in per cent)

\begin{tabular}{|lcccc|}
\hline Statistics & Mibor & Mifor & Libor & Mibor-Mifor spread \\
\hline Mean & 7.00 & 5.27 & 3.03 & 1.73 \\
\hline Standard Error & 0.21 & 0.25 & 0.19 & 0.17 \\
\hline Median & 6.25 & 5.02 & 2.94 & 1.31 \\
\hline Standard Deviation & 1.96 & 2.29 & 1.70 & 1.59 \\
\hline Kurtosis & -0.48 & 0.67 & -1.54 & 1.11 \\
\hline Skewness & 0.72 & 0.36 & 0.19 & 0.95 \\
\hline Range & 7.19 & 12.36 & 4.97 & 8.46 \\
\hline Minimum & 4.49 & 0.33 & 0.52 & -1.72 \\
\hline Maximum & 11.69 & 12.69 & 5.49 & 6.74 \\
\hline
\end{tabular}

Table 1b. Summary Statistics of 1 Year Rates (in per cent)

\begin{tabular}{|lcccc|}
\hline Statistics & Mibor & Mifor & US swap & Mibor-Mifor spread \\
\hline Mean & 5.86 & 5.01 & 3.08 & 0.85 \\
\hline Standard Error & 0.15 & 0.20 & 0.18 & 0.13 \\
\hline Median & 5.51 & 4.98 & 2.96 & 0.63 \\
\hline Standard Deviation & 1.37 & 1.86 & 1.62 & 1.23 \\
\hline Kurtosis & 0.35 & -0.25 & -1.50 & 0.42 \\
\hline Skewness & 0.76 & 0.36 & 0.14 & 0.61 \\
\hline Range & 6.30 & 8.50 & 4.97 & 6.61 \\
\hline Minimum & 3.66 & 1.78 & 0.63 & -1.76 \\
\hline Maximum & 9.95 & 10.28 & 5.60 & 4.85 \\
\hline
\end{tabular}

Table 2. Dickey Fuller Unit Root Tests

\begin{tabular}{|lllll|}
\hline \multirow{2}{*}{ Variable } & \multicolumn{2}{c|}{ Test statistic (levels) } & \multicolumn{2}{l|}{ Test statistic (first difference) } \\
\cline { 2 - 5 } & 1 year & 3 month & 1 year & 3 month \\
\hline Mibor & -1.472 & -1.327 & -6.879 & -8.275 \\
\hline Mifor & -1.642 & -2.573 & -8.388 & -10.729 \\
\hline Libor & -0.270 & -0.626 & -7.057 & -7.518 \\
\hline
\end{tabular}

Note: Critical value at $1 \%$ is -3.535 , and -2.904 at $5 \%$.

Table 3a. Engle-Granger Test of Cointegration between Domestic and Covered Interest Rates

\begin{tabular}{|llllll|}
\hline \multicolumn{3}{|c}{3 month rates } & \multicolumn{3}{c|}{1 year rates } \\
\hline ADF (lag 4) & LM(1) & LM (4) & DF & LM(1) & LM (4) \\
\hline-1.7638 & 0.0474 & 5.1369 & -2.3526 & 1.7056 & 8.9505 \\
\hline
\end{tabular}

Note: LM(1) and LM(4) are Lagrange-Multiplier test statistics and test for autocorrelation of up to the first and fourth order respectively. The $5 \%$ significance level critical values are as follows: DF statistic, -2.89; ADF statistic, -3.39; LM(1) statistic, 3.84; and LM(4) statistic, 9.49.

Table 3b. Test of Cointegration for Mibor and Mifor Under Different Restrictions

\begin{tabular}{|c|c|c|c|c|c|c|c|c|}
\hline \multirow[t]{3}{*}{ Submodel for one year $(1 \mathrm{yr})$ and three month $(3 \mathrm{~m})$ Data } & \multicolumn{4}{|c|}{$\begin{array}{l}\text { Maximum eigenvalue } \\
\text { test }\left(\lambda_{\max }\right)\end{array}$} & \multicolumn{4}{|c|}{ Trace test $\left(\lambda_{\text {trace }}\right)$} \\
\hline & \multicolumn{2}{|c|}{$1 \%$ level } & \multicolumn{2}{|c|}{$5 \%$ level } & \multicolumn{2}{|c|}{$1 \%$ level } & \multicolumn{2}{|c|}{$5 \%$ level } \\
\hline & $1 \mathrm{yr}$ & $3 \mathrm{~m}$ & $1 \mathrm{yr}$ & $3 \mathrm{~m}$ & $1 \mathrm{yr}$ & $3 \mathrm{~m}$ & $1 \mathrm{yr}$ & $3 \mathrm{~m}$ \\
\hline Model 0. Trend (None) & $\left.0^{*}\right)$ & 0 & $\left.0^{*}\right)$ & 0 & 0 & 0 & 0 & 0 \\
\hline Model 1*. Trend (rconstant) & 0 & 0 & 0 & 0 & 0 & 0 & 0 & 0 \\
\hline Model 1. Trend (constant) & 0 & 0 & 0 & 0 & 0 & 0 & 0 & 0 \\
\hline Model 2*. Trend (rtrend) & 0 & 0 & 0 & 0 & 0 & 0 & 0 & 0 \\
\hline Model 2. Trend (trend) & 0 & 0 & 0 & 0 & 0 & 0 & 0 & 0 \\
\hline
\end{tabular}

Note: ${ }^{*}$ Indicates the rank ( $r$ ) is zero. The null hypothesis of no cointegration cannot be rejected at the $5 \%$ and $1 \%$ level. The results shown here are based on four lags for the 1-year data (1 yr), and 3 lags for the 3-month data (3m) indicated by the AIC tests as optimal. 
Table 4. Augmented Dickey Fuller (ADF) Unit Root Test for Spread.

\begin{tabular}{|lllll|}
\hline \multirow{2}{*}{ Variable } & \multicolumn{2}{l|}{ Test statistic } & \multicolumn{2}{l|}{ First difference of test statistic } \\
\cline { 2 - 5 } & $1 \mathrm{yr}$ & $3 \mathrm{~m}$ & $1 \mathrm{yr}$ & $3 \mathrm{~m}$ \\
\hline Spread & -2.02 & -1.96 & -4.28 & -6.12 \\
\hline Absolute spread & -2.40 & -1.98 & -4.28 & -5.93 \\
\hline
\end{tabular}

Note: Four lags are used. The critical values are -4.09 and -3.47 at the $1 \%$ and $5 \%$ significance level. A trend is included in the ADF test. The coefficient on the trend variable in the ADF test in all cases is highly insignificant.

Table 5. Test of Cointegration for Mibor, Mifor and Libor Under Different Restrictions

\begin{tabular}{|c|c|c|c|c|c|c|c|c|}
\hline \multirow{3}{*}{$\begin{array}{l}\text { Submodel For one year(1 yr) and three month } \\
(3 \mathrm{~m}) \text { Data }\end{array}$} & \multicolumn{4}{|c|}{ Maximum eigenvalue test $\left(\lambda_{\max }\right)$} & \multicolumn{4}{|c|}{ Trace test $\quad\left(\lambda_{\text {trace }}\right)$} \\
\hline & \multicolumn{2}{|c|}{$1 \%$ level } & \multicolumn{2}{|c|}{$5 \%$ level } & \multicolumn{2}{|c|}{$1 \%$ level } & \multicolumn{2}{|c|}{$5 \%$ level } \\
\hline & $1 \mathrm{yr}$ & $3 \mathrm{~m}$ & $1 \mathrm{yr}$ & $3 \mathrm{~m}$ & $1 \mathrm{yr}$ & $3 m$ & $1 \mathrm{yr}$ & $3 \mathrm{~m}$ \\
\hline Model 0. Trend (None) & $0^{\text {a) }}$ & 0 & $0^{\text {a) }}$ & 1 & 0 & 0 & 0 & 0 \\
\hline Model 1*. Trend (rconstant) & 0 & 0 & 0 & 0 & $0^{\mathrm{b})}$ & 0 & $1^{\mathrm{b})}$ & 0 \\
\hline Model 1. Trend (constant) & 0 & 0 & 0 & 0 & 0 & 0 & 1 & 1 \\
\hline Model 2*. Trend (rtrend) & 0 & 0 & 0 & 0 & 0 & 0 & 1 & 0 \\
\hline Model 2. Trend (trend) & 0 & 0 & 0 & 0 & 0 & 0 & 0 & 0 \\
\hline
\end{tabular}

Note: ${ }^{\text {a) }}$ Indicates the rank $(r)$ is zero. The null hypothesis of no cointegration cannot be rejected at the $1 \%$ level. ${ }^{\text {b) }}$ Indicates the rank $(r)$ is one. The null hypothesis of no cointegration is rejected at the $5 \%$, but not at the $1 \%$ level.

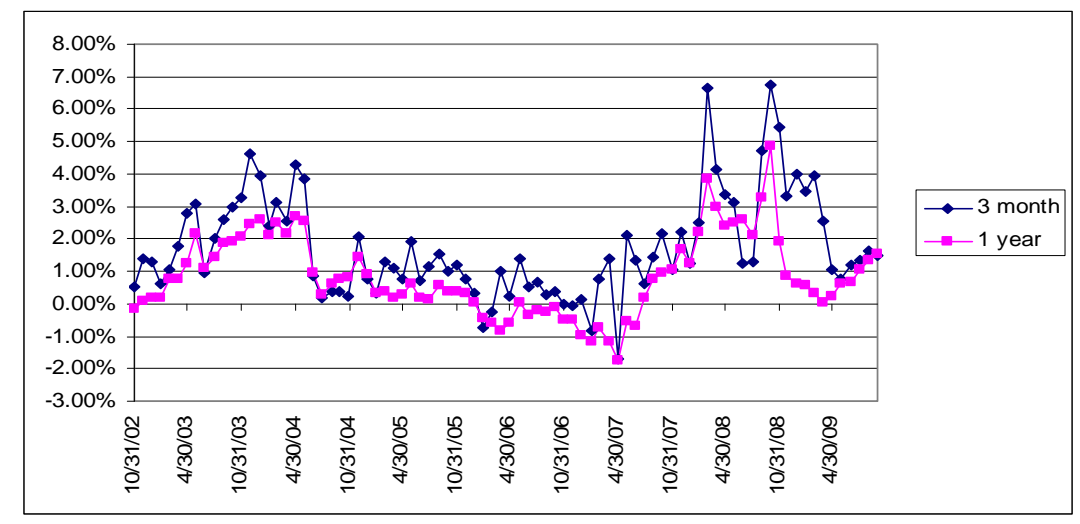

Figure 1. Plot of Mibor-Mifor Spreads 